\title{
Behavioral Integrity: The Perceived Alignment Between Managers' Words and Deeds as a Research Focus
}

Tony Simons: Cornell University, School of Hotel Administration, Statler Hall 538, Ithaca, New York 4853-6902

\begin{abstract}
This paper focuses on the perceived pattern of alignment between a manager's words and deeds, with special attention to promise keeping, and espoused and enacted values. It terms this perceived pattern of alignment "Behavioral Integrity." The literatures on trust, psychological contracts, and credibility combine to suggest important consequences for this perception, and literatures on hypocrisy, social accounts, social cognition, organizational change, and management fashions suggest key antecedents to it. The resulting conceptual model highlights an issue that is problematic in today's managerial environment, has important organizational outcomes, and is relatively unstudied.
\end{abstract}


A rapidly growing body of literature recognizes that trust plays a central role in employment relationships. Though scholars have varied somewhat in their specific definitions of trust, there is substantial agreement that a perception that another's words tend to align with his deeds is critically important for the development of trust (e.g., McGregor 1967). Credibility has received recent attention in the practitioner literature (Kouzes and Posner 1993) as a critical managerial attribute that is all too often undermined by managers' word-deed misalignment. In a similar vein, psychological contracts research has proliferated in recent years, due in part to its relevance in the recent managerial environment of widespread downsizing and restructuring because these processes are often understood by workers as violations of employers' commitments (Robinson 1996). This paper contends that the perceived pattern of managers' worddeed alignment or misalignment- with regard to a variety of issues-is it- self an important organizational phenomenon because it is a critical antecedent to trust and credibility. This perception is affected not only by management's adherence to psychological contracts, but also by phenomena that are less immediate or close to the employee, such as managers' behavioral adherence to espoused values, mission statements, and other short- and long-term commitments and self-descriptions.

Focusing attention on the perception of managers' word-deed alignment highlights several organizational phenomena as likely sources of influence upon both the managers' actual word-deed alignment and employees' perception of it. Further, this focus generates testable research propositions and practical suggestions for managing employee trust in management and the con- sequent organizational outcomes. This paper will argue that this perception, which we term "behavioral integrity," warrants further study because of its central conceptual role and because of its potential for managerial prescription.

Trust has become widely recognized as a central outcome and antecedent in organizational studies. Trust, however, is a very complex construct that is variously conceived to include a wide range of cognitions, emotions, attitudes, and actions (Kramer 1999). The psychological contract is powerful in its relevance and its implications, but applies only to reciprocal commitments that are proximal to the employee-it does not address the far wider range of perceived managerial word-deed misalignments which, this paper argues, seriously undermine trust in management relationships. Behavioral integrity $(\mathrm{BI})$ is proposed here as a central but manageable antecedent to trust that describes a wider range of 
organizational experiences than the psychological contract. The present work hopes to promote and structure inquiry into this realm.

Figure 1 shows a model of the conceptual linkages that will be argued here. This paper will first draw from literatures on trust, credibility, and psychological contracts to delineate the construct of behavioral integrity and its organizational consequences (Figure 1, Block $\mathrm{A}$ ). As $\mathrm{BI}$ is a subjectively perceived phenomenon, literatures on social cognition and

Figure 1 Conceptual Diagram of Antecedents and Consequences of Behavioral Integrity

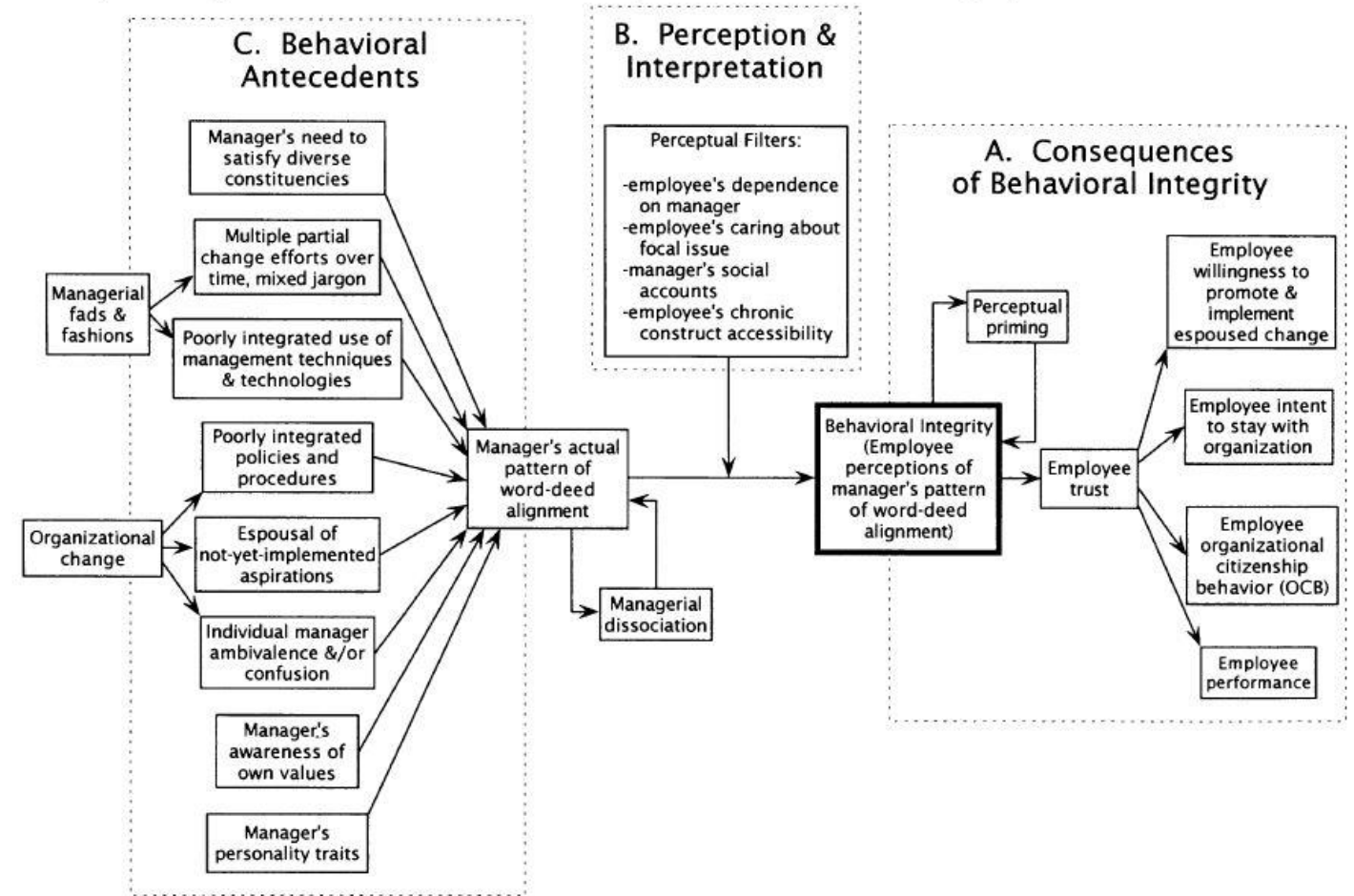

social accounts describe the conditions under which actual managerial word-deed alignment or misalignment will be perceived and interpreted in such a way as to influence ascriptions of behavioral integrity (Figure 1, Block B). Finally, literatures on institutional tasks, managerial fashions, and organizational change will be used to consider causes of actual managerial word-deed alignment or misalignment, which in tum serves as the basis for perception (Figure 1, Block C). As can be inferred from the literatures invoked, this model crosses levels of analysis, from institutional and organizational forces to manager responses to employee perceptions of and reactions to managers and back to organizational outcomes.

\section{Construct Definition}

Behavioral Integrity (BI) Is the Perceived Pattern of Alignment Between an Actor's Words and Deeds. It entails both the perceived fit between espoused and enacted values, and perceived promise-keeping. 
Thus, it includes the perception of behavioral adherence to psychological contracts, as well as to mission statements, corporate value statements, descriptions of individual values, priorities, or management styles, and simple follow-through on expressed commitments. In an organizational context, $\mathrm{Bl}$ is typically conceived as employees' perceptions of their managers' pattern of word-deed alignment, but applications in other contexts are readily conceivable. Be- cause $\mathrm{BI}$ is a perceived pattern of alignment or misalignment, generally based on observations over time, it entails internal attributions and may be considered an ascribed "trait."

In other words, $\mathrm{Bl}$ is the extent to which employees perceive that their managers tend to represent themselves and their motivating values accurately in their communications with employees. $\mathrm{BI}$ is the extent to which employees believe a manager "walks her talk," and, conversely, it reflects the extent to which they see her as "talking her walk."

The Random House College Dictionary (1975, p. 692) defines integrity as "adherence to moral and ethical principles." As defined here, though, $\mathrm{BI}$ does not consider the morality of principles, but rather focuses on the extent to which stated principles are seen as aligning with actions. Thus, a colleague who openly advocates self-interest, rather than the common good, as a basis for personal actions might be despised if one does not share his values. However, such a colleague might be seen as having high behavioral integrity if one can see clear alignment between word and deed. One might not support the colleague's actions or seek

\begin{tabular}{|c|c|}
\hline Behavioral Integrity & $\begin{array}{l}\text { Ascribed trait, describing a perceived pattern of alignment between another's words and deeds. } \mathrm{Bl} \text { is a } \\
\text { present-time trait whose ascription draws on history. }\end{array}$ \\
\hline $\begin{array}{l}\text { Trust (from Mayer et al. } \\
\text { 1995, p. 712) }\end{array}$ & $\begin{array}{l}\text { The willingness of a party to be vulnerable to the actions of another party based on the expectation that the } \\
\text { other will perform a particular action important to the trustor, irrespective of the ability to monitor or control } \\
\text { that other party. While } \mathrm{BI} \text { looks back to the past, trust looks forward toward future decisions. By this } \\
\text { definition, one would expect } \mathrm{BI} \text { to be one of a few key antecedents to trust. }\end{array}$ \\
\hline $\begin{array}{l}\text { Credibility (from O'Keefe } \\
\text { 1990, p. 130) }\end{array}$ & $\begin{array}{l}\text { A perceiver's assessment of believability, or of whether a given speaker is likely to provide messages that } \\
\text { will be reliable guides to belief and behavior. This construct, widely discussed in persuasion, marketing, } \\
\text { and legal literatures, largely overlaps with trust, and may be considered as a subclass of trust. Credibility, } \\
\text { like trust, is forward looking. Like trust, one would expect credibility to be affected by BI and other factors. }\end{array}$ \\
\hline $\begin{array}{l}\text { Psychological Contracts } \\
\text { (from Rousseau and } \\
\text { McLean Parks 1993) }\end{array}$ & $\begin{array}{l}\text { Individual's beliefs regarding a reciprocal exchange agreement based on perceived implicit or explicit } \\
\text { promises. If an employee perceives a psychological contract violation in the workplace, he is extremely } \\
\text { likely to downgrade his ascription of his employer's BI. Psychological contract violations may be } \\
\text { understood as especially egregious and salient perceived word-deed misalignments. }\end{array}$ \\
\hline $\begin{array}{l}\text { Hypocrisy (from Brunsson } \\
\text { 1989, p. 205) }\end{array}$ & $\begin{array}{l}\text { Inconsistency between talk and action, presentation and results. Hypocrisy, like BI, is anchored in past } \\
\text { actions. Hypocrisy may be considered as an antonym of BI. Most treatments of hypocrisy are } \\
\text { unsympathetic to the actor in part because they do not acknowledge the role of the perceiver in defining } \\
\text { the presence or absence of word-deed alignment. }\end{array}$ \\
\hline
\end{tabular}

vulnerability to him, but at least one knows that he means what he says. The behavioral integrity definition used here draws on a secondary 
definition of integrity that describes elements fitting together into a seamless whole, as in the integrity of a boat hull (Random House 1975).

Perceivers can ascribe behavioral integrity or its lack to an individual person, or to a group of people, such as "this company's management" or "anyone over 31" or "politicians." To facilitate presentation, present discussion will focus on ascription of $\mathrm{BI}$ to a single person. While behavioral integrity is clearly a subjective assessment, it is based partly on the actor's conduct. Thus, one might meaningfully aggregate many people's perceptions of an actor's behavioral integrity to estimate, for example, the effect of a manager's conduct on departmental outcomes.

Table 1 summarizes the key construct definitions used in this exposition.

\section{Related Constructs}

Trust

While the construct of trust has received considerable re- cent attention, scholars have used diverse definitions of the construct (Bigley and Pearce 1998, Kramer 1999). Though there seems to be a shared intuitive "sense" of the type of thing trust represents, specific definitions of trust have focused on expectations, action patterns, intent, risk and vulnerability, ethical justifiability, and/or value congruence. The intent of this discussion is not to present an exhaustive list of extant trust definitions-this task is admirably pursued by Kramer (1999) and Bigley and Pearce (1998). Instead, the intent is to establish the following points: (1) Within several widely used trust definitions, the perception or belief that another's words have historically aligned with deeds is recognized either as a central antecedent to trust, or as a component of trust itself; (2) Trust definitions that include perceived word- deed alignment among other beliefs or perceptions as elements of trust itself risk short-circuiting the scientific exploration of the interplay between the various antecedents of trust.

Some definitions focus on trust as a psychological state of willingness. Mayer et al. (1995, p. 712) present a definition of trust that has been widely cited in recent theoretical research (Rousseau et al. 1998). They define trust as "the willingness of a party to be vulnerable to the actions of another party based on the expectation that the other will perform a particular action important to the trustor, irrespective of the ability to monitor or control the other party." According to Mayer et al., perceptions of another's integrity, ability, and benevolence form the three critical antecedents to trust. Mayer's et al.'s definition of trust will be used for the model development element of the present article. 
Other definitions of trust focus less on willingness and more on the aspect of expectation or belief. Hosmer (1995, p. 393) synthesizes definitions from previous work and proposes that "trust is the reliance ... upon a voluntarily accepted duty on the part of another ... to recognize and protect the rights and interests of all others engaged in a joint endeavor or economic exchange." Robinson (1996) defines trust as "one's expectations or beliefs about the likelihood that another's future actions will be beneficial, or at least not detrimental, to one's own interests." These positive expectations should be based largely on the ascription of benevolence and value or goal congruity.

Additional definitions of trust have emerged from economic traditions. Tyler and Kramer (1996) draw on Williamson's (1993) game-theoretic definition of trust as a probabilistic estimate of future cooperation. While this definition shares evident characteristics with the aforementioned definitions, the notion of trust as a "probabilistic estimate," rather than as a "reliance upon" or a "willingness," links to different scholarly traditions, generates different operationalizations, and points toward different interventions. Such calculative trust conceptualizations draw upon the notion of value or goal congruity, but emphasize behavioral reliability as a formative mechanism (Lewicki and Bunker 1996).

Sitkin and Roth (1993) take these two evident antecedents to trustascribed goal or value congruity and reliability-and link them to different constructs. They propose that trust emerges from the perception of another's task-specific reliability, while mistrust emerges from perception of a more generalized value incongruity with the other. This brief and incomplete sampling of trust definitions shows trust as a willingness to make oneself vulnerable and as an expectation of benevolent, cooperative, or nonhindering actions. Various trust definitions emphasize perceived behavioral reliability and perceived goal congruity as key drivers of trust and/or mistrust. We propose that $\mathrm{Bl}$ is likely to affect trust and mistrust through both the mechanisms of perceived reliability and of perceived value or goal Gongruity.

Lewicki and Bunker (1996) offer a longitudinal perspective for the role of behavioral integrity in the establishment of trust. In their conceptual framework, "deterrence-based trust (sometimes called 'calculus- based trust') is based on constancy of behavior-that people will do what they say they are going to do" (p. 118). Lewicki and Bunker propose a sequential development in work relationships from calculus-based trust to more intimate, empathic, and exclusive forms of trust. These authors argue that a failure at any of these types of trust precludes progress to the next level of 
trust. By this reasoning, a failure to "do what you say you are going to do" might completely arrest the development of trust. McAllister (1995) proposes a distinction between cognition- based trust, which is based on a perception of reliability and dependability, and affect-based trust, which is based on reciprocated care and concern. McAllister argues that a perception of past follow-through on commitments-a perception of $\mathrm{BI}$-is critical for cognition-based trust (p.28). McAllister then develops a sequential argument similar to Lewicki and Bunker's (1996). He proposes cognition-based trust as a necessary precursor to the development of affect-based trust because people must be confident in their expectations of another's reliability and dependability before they make further emotional investment in a relationship (p. 30). Within both of these different frameworks, then, a person who is perceived as not doing what he says might have substantial difficulties in establishing any trust at all. These two frameworks suggest that a perception of behavioral integrity may be a necessary condition for the establishment of trust. We believe these arguments emerge from a sense of trust as springing from behavioral reliability-that the speaker's words provide the listener with some sense of certainty regarding the actions that will follow.

A second way in which the perception of speech that is misaligned with actions (or vice versa) undermines trust is through norms of reciprocity, which, Fox (1974) argues, emerge from an ascription of goal or value in- congruity. Mistrust, it is often said, begets mistrust (Fox 1974, Zand 1972). If employees believe that their man- agers are unwilling to present them with unvarnished representations of their actual values, they can easily infer that their managers do not trust them enough to tell the truth. When employees perceive that their managers do not trust them, they tend in tum to mistrust those man- agers (Fox 1974). Butler (1995) describes a cycle of reciprocity whereby if one party is not forthcoming, then the other party in tum lowers his trust in the first, and be- comes less likely to enact cooperative behavior. Zand (1972, p. 230) describes this phenomenon in groups as a "short-cycle feedback loop," whereby mistrust generates cautious behaviors which, in tum, stimulate mistrust on the part of others. Creed and Miles (1996, p. 19) focus this reciprocity on the managerial relationship. They note that managers initiate most vertical exchanges, and, in consequence, whatever level of trust or mistrust is evident in their actions will, through reciprocation, set the tone for the relationship. Employees may interpret their perception of managers' poor word-deed alignment as a cue that managers mistrust them, and respond by reciprocation. 
Fox (1974) makes the argument that the reciprocity of mistrust emerges from an employee's inference from management's demonstration of mistrust that management must hold goals or values that are incompatible with those of the employee. Thus, it is possible that employees' inferences will extend beyond the belief that the manager has chosen to misrepresent priorities, and will explore sinister guesses as to the content of the underlying "true" priorities. A subordinate is likely to reason as follows: "If my manager does not trust me enough to honestly account for her behavior, perhaps it is because she is pursuing goals or values of which she knows I do not approve." Employees might infer value incongruence with their manager from their perception of their manager's word-deed misalignment and, thus, come to trust that manager less. These arguments reinforce the notion that behavioral integrity affects trust both through perceived behavioral reliability and through employee inferences about managers' goal or value congruity.

Several conceptualizations of trust have been explicitly multidimensional. Mishra (1996, p. 265) draws on the concept of willingness to be vulnerable, but borrows from several other sources to define trust as "one party's willingness to be vulnerable to another party based on the belief that the other party is (a) competent, (b) open, (c) concerned, and (d) reliable." Cummings and Bromiley (1996) take a similarly multipronged approach as they propose that trust is one person's belief that another (a) makes good-faith efforts to act in accordance with commitments, (b) was honest in the negotiations that preceded such commitments, and (c) will not be excessively opportunistic in taking advantage.

These multidimensional approaches begin to blur the lines between the phenomenon of trust and its antecedents. If trust is defined as having multiple component beliefs, then what happens to trust when some of those beliefs are held and some are not? Does trust function additively, or according to the minimum component, or is it computed in some other more intricate or context- specific manner? Multidimensional trust definitions risk short-circuiting the exploration of the relative importance and interplay between the described components of trust. While some theoretic work has begun to propose solutions to these questions (e.g., Kramer 1999), the operationalizations required for empirical testing, and the theories to be tested, have not developed widespread agreement. For the purposes of the present concept development, we will accept that these multidimensional trust definitions accord central causal impact to notions similar to behavioral integrity, and we encourage proponents of 
multidimensional trust construct definitions to articulate and examine the interplay between the different elements that they propose comprise trust. We propose, however, that research into this important area is facilitated by making a clear distinction between $\mathrm{BI}$ and the more complex phenomenon of trust.

The well-documented notion that perceived alignment between word and deed influences trust leads to the following proposition:

PROPOSITION 1. Increases or decreases in behavioral integrity ascriptions will increase or decrease trust, respectively. This influence will function through the mechanisms of perceived reliability and perceived value or goal congruence.

\section{Credibility}

Credibility, as discussed in the persuasion literature, is an assessment of believability, or of whether a given speaker is likely to provide messages that will be reliable guides to belief and behavior (O'Keefe 1990). According to Aristotle and to many contemporary rhetoric scholars, ethos, or source credibility, is the most potent means of persuasion (Mccroskey and Young 1981). While common usage implies that credibility is an attribute of the message sender, communications scholars consider it rather to be a judgment (O'Keefe 1990) or an attitude (Mccroskey and Young 1981) on the part of the perceiver with regard to a given communicator.

As has been the case with trust, the construct of credibility has often been considered to be multidimensional, comprising the perceiver's assessment of the communicator's relevant knowledge, veracity, and good intentions toward the perceiver (Mccroskey and Young 1981). The three agreed-upon dimensions of credibility parallel the three critical antecedents to trust as detailed by Mayer et al. (1995). Behavioral integrity probably most strongly affects the latter two: veracity and good intentions or benevolence. Allowing a speaker's utterance to influence one's important decisions and behavior places one in a position of vulnerability to that speaker and is thus an expression of trust. This discussion considers credibility, then, to be an important subclass of the broader phenomenon of trust.

The concept of source or communicator credibility has been extensively researched in the study of attitudes and attitude change. Laboratory studies of attitude change have manipulated credibility through information about the source's expertise on the subject and their motive to 
misrepresent information through vested interest in the outcome (Eagly and Chaiken 1993, Fiske and Taylor 1991). These manipulations are very relevant to marketers, as spokespeople and salespeople clearly vary on these two attributes. Legal writings on witness credibility have emphasized a third (and perhaps dominant) contributing factor: Credibility may be seriously undermined by evidence of the witness's prior misrepresentation of related or unrelated issues. "The fact that the witness previously engaged in deception tends to show the witness has a character trait for untruthfulness, and in tum the existence of that character trait at least slightly increases the probability that the witness lied during his testimony" (Strong 1999, p. 150).

A few managerial texts and substantial social psychological research on attitudes have focused on credibility issues that are central to the current work. Kouzes and Posner (1993) argue that managers' credibility is necessary for the development of employee loyalty and commitment, and that its lack impedes a manager's effectiveness, as the managers' words lose power as instruments of change. Leaders' exhortations of a new mission or a new focus are processed by employees as simply a new dogma or corporate presentation, and are not translated into action. An executive quoted in Mishra (1996, p. 267) describes this effect:

If they don't believe what I'm telling them, if they think it's all a bunch of bull, don't expect them to go out there and work a little harder or work a little different. They're not going to be as receptive to change unless they understand and trust that the things we're talking about are in fact true.

The extent to which employees are willing to be influenced by their managers' words is critical for effective management and change implementation. Words are one of a manager's most potent tools for guiding subordinates at all levels of the company. When credibility is sacrificed, the manager damages that tool, and is forced into additional actions to show when he "really means" what he says. Kouzes and Posner argue that managers earn and strengthen their credibility when they simply do what they say they will do.

Scholars of various traditions would agree that the perception of behavioral integrity has a very direct impact on credibility. Behavioral integrity is backward-looking and focuses on the past pattern of alignment between words and deeds. Credibility, on the other hand, is forwardlooking, and entails the extent to which the speaker's statements can be relied upon to accurately guide future action. Further, credibility is affected 
by assessments of expertise, veracity, and benevolence, while $\mathrm{BI}$ takes into account only the perception of the speaker's prior pattern of word-deed alignment. One might assert that assessments of $\mathrm{BI}$, based on past experience, are one of a few key factors that affect judgments of managers' credibility. $\mathrm{Bl}$ is distinct from credibility, and we understand credibility to reflect a subset of the larger phenomenon of trust.

\section{Psychological Contracts}

The psychological contract is a construct that is closely related to trust, and is seldom discussed without evoking trust (Robinson 1996). "The term psychological contract refers to an individual's beliefs regarding the terms and conditions of a reciprocal exchange agreement between that person and another party" (Rousseau and McLean Parks 1993, p. 19). Psychological contracts differ from general employee expectations in that psychological contracts must emerge from perceived explicit or implicit promises (Robinson 1996, Rousseau 1995, Rousseau and McLean Parks 1993), and the perceived violation of these promises tends to elicit a sense of "moral outrage" (McLean Parks 1997). In the organizational context, most empirical research on psychological contracts has focused on the employee's perception of the promises made by the employer in exchange for the employee's service. Given its promissory basis, employees perceive the violation of a psychological contract as a word-deed misalignment that undermines ascriptions of managers' integrity, and also undermines beliefs in managers' benevolence (Robinson 1996). The mechanism that Robinson proposes appears to apply to perceived word- deed misalignments in general. The perception of man- agers' adherence to psychological contracts may be considered as an especially potent antecedent to $\mathrm{BI}$.

Many perceived managerial word-deed misalignments are not psychological contract violations, but they would still be expected to affect behavioral integrity. The manager who espouses participative, consensus decision making, but who ultimately forces his decisions on the group, is vulnerable to accusations of low Bl. The same is true of the organization that proudly proclaims its commitment to customer service, but whose policies, incentives, and daily management behavior belie that commitment. Consider the employees at an organization that has undergone-and at different times espoused-multiple superficially implemented change efforts. As experienced employees become increasingly cynical (Kanter and Mirvis 1989), lofty management proclamations cease even to influence employee expectations and their 
psychological contracts. However, the accumulation of perceived falsehoods, as they are seen as a pattern, affects BI and thus affects employees' trust in management.

A psychological contracts argument might be applied to account for the sort of problems described above (e.g., Rousseau 1995, pp. 80-82). However, a strict definition of psychological contracts would limit discussion to the direct exchange agreement between the employee and the employer or manager. In the examples provided above, it seems doubtful that the employee would interpret the word-deed misalignments from so personal a standpoint, or would experience responses as intense as moral outrage. These misalignments are not focused on the employee, and while they may be upsetting, they do not substantially threaten the fundamental exchange agreement. However, in all these cases, some form of promissory breach or word-deed misalignment has occurred that could well influence the relationship between manager and employee. The $\mathrm{Bl}$ framework is more general than psychological contracts, and focuses simply on the employee's perception that the manager's words tend or tend not to align with his deeds. This simple perception is sufficient to account for substantial consequences.

The Bl framework addresses a broad set of phenomena that are in many ways similar in consequence to psychological contracts, but are not addressed by that construct. The psychological contracts framework focuses on a set of perceived word-deed alignments and misalignments that directly regard the employee's well-being. In this context, it focuses exclusively on the employee's perception of what is said or promised to them, and does not consider the impact of the employer's treatment of others or the employer's general mode of conducting business, except as those occurrences have implications for the employee's own contract. Both sorts of breach would be considered as drivers of BI. BI considers proximal breaches, but also considers those that have more distal consequences.

Though the study of psychological contract violations is relatively new, initial research results suggest that these violations have important consequences. Rousseau and McLean Parks (1993, p. 36) propose that "contract violation erodes trust, [and] undermines the employment relationship yielding lower employee contributions (e.g., performance and attendance) and lower employer investments (e.g., retention, promotion)." Blancero and Johnson (1997) further proposed that psychological contract violation is likely to influence customer service employees's "discretionary service behaviors." Robinson (1996) empirically explored the consequences of contract breach, and found that a breach reduced trust 
and that this reduction in tum reduced employee performance, intent to remain with the organization, and civic virtue behavior. The consequences of contract violation as described by Rousseau and McLean Parks (1993), Robinson (1996), and Blancero and Johnson (1997), as documented above, should apply also to the broader phenomenon of behavioral integrity.

PROPOSITION 2. Trust will mediate positive relationships between $\mathrm{Bl}$ and employee performance, intent to remain, organization citizenship behavior, and discretionary service behavior.

\section{The Attributes of Behavioral Integrity}

The preceding discussion of the relationship between $\mathrm{BI}$ and similar constructs informs our understanding of the consequences of the $\mathrm{Bl}$ construct, but comparison to simi-lar constructs may also be used to further inform our understanding of the nature of the construct itself. Specifically, behavioral integrity is understood as (1) a subjectively ascribed (2) trait that (3) may be unitary or domain-specific, (4) may be ascribed to individuals or groups, and that (5) exhibits asymmetry between its enhancement and diminishment. These five assertions will be discussed in sequence.

$B$ I Is Subjective. Trust, psychological contracts, and credibility are all described as fundamentally subjective in nature. Lewicki and Bunker (1996, p. 132) note that "if trust has been broken in the eye of the beholder, it has been broken." Rousseau and McLean Parks (1993) make the same point about psychological contracts. Kouzes and Posner (1993, p. xxii) note that "credibility is determined by the constituents." Given this consistency across frame- works, it seems prudent to consider that the impact of behavioral integrity emerges from the perceived pattern of alignment between managerial words and deeds.

The subjective nature of this construct means that man- aging behavioral integrity is no simple feat. As Weick (1995, p. 182) notes, ". . . when a manager walks the talk in the eyes of one subordinate, that walking is seen as insincere by someone else who links it with a different set of words." The subjective nature of the BI construct means that the perceiver is intimately involved in the way $\mathrm{Bl}$ is construed and that $\mathrm{Bl}$ is likely to be influenced by the actor, by the relationship between the actor and the perceiver, and by the attributes, history, and state of mind of the perceiver.

Despite this subjectivity, however, perceptions of behavioral integrity are at least somewhat influenced by the actual object of perception-the 
actor's conduct. Individual differences between perceivers will influence assessments of $\mathrm{BI}$, but these differences can be attenuated through aggregation. Thus, an averaged perception by a department's employees of their manager is likely to say something meaningful about that manager's actions and/ or his ability to manage employee perceptions.

$B I$ Is an Ascribed Trait. If a person's deeds do not align with their words, the fundamental attribution error (Heider 1958) proposes that perceivers will tend to attribute the actor's behavior to dispositional qualities rather than to situational factors. Thus, observers tend to ascribe misalignments to traits (for example that a person is "in-sincere" or is a "hypocrite" or a "liar") rather than to a more subtle account of the situational exigencies that motivated the behavior. Internal attributions would be further strengthened by the fact that $\mathrm{BI}$ reflects a perceived pattern of worddeed alignment observed over time (Kelley 1967). March (1979) argues that most people's implicit understandings of psychology include strong assumptions that actions are rationally chosen to optimize the actor's pursuit of goals and values. This argument suggests that even when the words and deeds in question are not explicitly focused on values, BI may often be understood by observers as a pattern of alignment or misalignment between the actor's espoused and enacted values. These arguments in combination suggest that behavioral integrity is likely to be perceived as a trait or a relatively stable attribute of the actor.

Is BI Unitary or Domain Specific? Lewicki et al. (1998) describe trust as "confident positive expectations about another's behavior," and mistrust as "confident negative expectations..." Lewicki et al. propose that both trust and mistrust are domain specific, and that human relationships contain ambivalence and full, complex mixtures of both trust and mistrust. This proposition that trust and mistrust may not be polar opposites echoes that of Sitkin and Roth (1993), but emphasizes that the two may well be specific to particular domains. This assertion raises a similar uncertainty regarding behavioral integrity: It is not yet clear whether the ascription of behavioral integrity is unitary or domain specific. For example, if one's manager truly means what she says when she expresses concern for customer service, but that same manager's talk about participative management is so much smoke, does the employee combine the two perceptions into a single $\mathrm{BI}$ judgment, or two? It is possible that the breadth or domain specificity of the ascription varies with the observer's personality or cultural traits. Ultimately, the question can be addressed by empirical study.

Perceivers Ascribe Bl at Multiple Levels. The entity to which behavioral integrity is ascribed can be a person or a group of people. 
Mayer and Davis (1996) note that in small organizations, the organization and its top decision makers are equivalent for the purposes of trust, but that in larger organizations, it is harder to determine who makes decisions; thus, in large organizations, the organization takes on a life of its own as a referent for trust. These authors describe employees' "aggregate" levels of trust or mistrust for management in their organizations. Mishra (1996) describes trust as "multi-level," in that it applies at different levels of hierarchy within organizations, and it also applies between organization s. Morrison and Robinson (1997, p. 228) argue with respect to psychological contracts that the organization assumes an anthropomorphic identity in the eyes of the employee. Rousseau (1995) similarly argues that employees tend to perceive that the organization has made a commitment, whether a promise was made by the owner, a manager, or a recruiter. Similarly, BI, or its lack, can be ascribed to individual actors, or, in larger organizations, to "management" or "the administration." For organizations where a particular leader is especially salient and is taken to personify the organization, these two kinds of ascription might be indistinguishable.

Disconfirmability and the Ratchet Effect. There is an asymmetry between the ease of confirming $\mathrm{BI}$ and violating it. Several researchers have argued that trust is slow to build and quick to dissipate. Burt and Knez (1996, p. 83) point out that "trust builds incrementally, but distrust has a more catastrophic quality." Kramer (1996) notes that violations of trust are more vivid than confirmations. Lewicki and Bunker (1996) describe calculus-based (early) trust as being like the game of chutes and ladders: trust builds in small steps, and a single misstep can cause a dramatic setback. This apparent asymmetry in the development of trust has prompted some scholars to distinguish trust and mistrust as distinct constructs (e.g., Sitkin and Roth 1993).

A social cognition approach can be used to explain more parsimoniously the asymmetry in trust development without bifurcating the trust construct. Reeder and Brewer (1979) examine the issue of personschema s, and propose that different ascribed attributes present different evidentiary requirements for the confirmation or disconfirmation of an ascription. These researchers note that the schema for "hypocrite" is extremely difficult to disconfirm once it is applied; any episodes of truthtelling can be easily construed as ultimately congruent with the overall schema because even a liar cannot lie all the time. A single lie might be enough to earn the actor the label of "liar," but it would take many spoken truths to shed that label. Thus, perceived word-deed misalignments exhibit 
a ratchet effect on $\mathrm{BI}$, where misalignments are tallied aggressively, but alignments are accorded substantially less weight.

Consideration of the asymmetry between the affirmation and disconfirmation of behavioral integrity leads to the following proposition:

PROPOSITION 3. Over a given time span, increases in BI should be small relative to decreases in $\mathrm{Bl}$. $\mathrm{Bl}$ changes more rapidly in a negative direction than in a positive direction.

\section{Social Cognition: When Will Word-Deed Alignment or Misalignment Be Perceived?}

Employees may fail to notice and process any given piece of evidence of managers' word-deed alignment or misalignment. Attention and cognitive energy are, after all, constrained resources (March and Simon 1958), and employees do not perceive and process everything around them. The following is a discussion of social cognition research that considers situational and individual factors that are likely to determine whether or not word-deed alignments and misalignments are perceived and interpreted in terms of behavioral integrity. In Figure 1, the discussion now focuses on Block B, "Perception and Interpretation."

\section{Situational Factor: Bosses, Subordinates, and BI}

The perception of behavioral integrity is likely to be strongly influenced by hierarchical relationships. There is evidence to suggest that subordinates are far more likely to notice $\mathrm{Bl}$ and its lack on the part of their managers than the other way around. This implication arises from research on attention and schema formation, and is further supported by observations in the more applied research on trust and leader credibility.

Observers' assessment of a manager's behavioral integrity is a perceptual and interpretational process, and is thus susceptible to distortions in social information processing. Berscheid et al. (1976) argue that employees focus substantial attention on their managers partly because they depend on them for rewards, promotions, favorable assignments, resources, and the like. As a result of this combined attention and dependency, employees tend readily to develop person-schemas for their managers (Erber and Fiske 1984). These schemas, in tum, lead employees to draw increased dispositional implications from managers' behavior, apparently to increase a sense of pre- diction and control (Berscheid et al. 1976, Erber and Fiske 1984). This framework is echoed by Kramer's (1996) notion of organization members as "vigilant and 
ruminative intuitive auditors" of their managers. There is substantial evidence from research on social cognition that people devote attention to their bosses, that they think about them often in their efforts to understand and predict their bosses' behavior, and that their preferred explanation for their bosses' behavior is to ascribe that behavior to personal traits or dispositions (Fiske and Taylor 1991). The fundamental attribution bias appears to increase when subordinates examine the behavior of their superiors (Erber and Fiske 1984, Fiske and Taylor 1991). A manager who violates his word because of an environmental exigency is unlikely to receive "benefit of the doubt" from his subordinates. This research suggests that those subordinates are fairly likely to notice word-action misalignment, and are likely to ascribe it to a personal trait of the manager. Both these tendencies serve to in- crease the sensitivity of employees' BI ascriptions.

This examination of behavioral integrity in hierarchical relationships leads to the following proposition:

PROPOSITION 4. Subordinates' perceptions of their managers' BI is likely to be more sensitive to actual word-deed misalignments than peer or superiors' evaluations of the same manager. This sensitivity might vary with the magnitude of the dependency relationship.

\section{Situational Factor: Importance of Focal Issue}

A second situational factor that is likely to influence the perception of $\mathrm{BI}$ is the importance of the espoused value, mission, or behavior pattern to the perceiver. While the discussion of organizational hierarchies focused on the importance of the actor to the perceiver, this issue focuses on the importance of the issue at hand to the perceiver. Cacioppo and Petty's elaboration likelihood model (1989) proposes that the personal relevance of a message increases motivation for central cognitive processing, which, in tum, influences attitudes. Thus, psychological contract breaches, as perceived behavioral misalignments with espoused exchange relationships, are extremely likely to trigger ascriptions of low $\mathrm{BI}$ because the issue at hand directly concerns the well-being of the perceiver, and is thus salient. On the other hand, a manager's behavioral misalignment with an espoused value placed on, for example, customer service, will be most salient to the employee who personally places a high value on service. This mechanism is described by Morrison and Robinson (1997) as the impact of issue salience on perceptions of unmet promises. Behavioral misalignment with espoused values will be most noticeable to those for whom the espoused 
value is important, and who are actively trying to translate that value into action. This notion is of practical consequence because the employees who become alienated as a result of this process are likely to be the organization's best employees-those who most strongly sup-port the organization's efforts to enact what it espouses. Consideration of this mechanism gives rise to the following proposition:

PROPOSITION 5. The more an employee cares about the focal issue, the more likely it is that the manager's relevant word-action alignments and misalignments will be noticed and will thus affect the employee's ascription of that manager's Bl.

\section{Situational Factor: Social Accounts}

Managers sometimes offer explanations and apologies for their behavior. Under certain specifiable circumstances, these explanations and apologies can influence observers' interpretations of a perceived worddeed misalignment. There is a growing literature on the impact of explanations, excuses, and apologies on perceived injustices (reviewed by Bies 1987, Greenberg 1990) and the management of conflict (reviewed by Sitkin and Bies 1993). Bies (1987) describes a typology of accounts for perceived injustices, and notes that different kinds of accounts operate in different ways. A discussion of these types will clarify the relationship between social accounts and behavioral integrity. While this literature typically refers to the person doing the explaining as the "wrongdoer," this discussion will use the term "manager" to recall the behavioral integrity context and to allow the possibility that a word-deed misalignment might not be ethically "wrong."

Causal accounts are attempts by the manager to disclaim responsibility for the action in question by showing how it was necessitated or caused by external circumstances. By offering a causal account, a manager attempts to modify employees' attributions for a given action. Because internal attributions for word-deed misalignment are integral to the behavioral integrity judgment, a successful causal account will reduce the interpretation of such misalignment as an indicator of behavioral integrity.

Ideological accounts attempt to evoke a superordinate goal or a driving value to rectify perceptions of injustice. It is an attempt to reframe the standard or value to which the behavior is compared. From a behavioral integrity perspective, an ideological account says, "Even though my actions were not in line with stated value $X$, consider that they were in line with stated value $\mathrm{Y}$, which is more important." A successful ideological 
account reduces the perception of word-deed misalignment by changing the words to which the deed is compared.

Referential accounts attempt to reduce the perception of wrongdoing by reducing the subordinates' sense of an unfavorable outcome. In essence, they say, "it is not so bad" or "it could be worse." It is not clear that referential accounts contribute meaningfully to the behavioral integrity framework.

Penitential accounts are apologies or expressions of remorse for the action. In an apology, the actor accepts responsibility for the action, but asserts the action does not represent what the actor is "really like" as a person. The statement that an action was unintentional represents something between a penitential account and a causal account (Bies 1987). From a behavioral integrity perspective, penitential accounts operate like causal accounts by attempting to modify the attributions that the perceiver makes for the word-deed misalignment.

Social accounts are especially critical to the behavioral integrity model because they represent the most straight-forward and least costly way that a manager can influence her subordinates' perception of her behavioral integrity. Because of this ease, social accounts may be overused (Sitkin and Bies 1993). The conditions under which social accounts are effective is the subject of a healthy and on-going research stream (reviewed by Bies 1987, Greenberg 1990, Sitkin and Bies 1993). Taken as a whole, this stream of research suggests the following proposition:

PROPOSITION 6. Social accounts will tend to reduce internal attributions for word-deed misalignments and will thus reduce their impact on BI.

\section{Individual Factor: Chronic Schema Accessibility}

People develop habitual dimensions upon which they assess and describe other people, and these dimensions would be considered to be chronically accessible to those observers (Fiske and Taylor 1991). Some people evaluate everyone they meet on intelligence; others might attune their attention to kindness, others to assertiveness. People who are chronicically attuned to a dimension are especially sensitive to it. They are more likely to notice that attribute, given a set of information (Bargh and Pratto 1986), and they are able to consider that attribute at times when nonchronics would be overloaded (Fiske and Taylor 1991). Higgins and King (1981) found that people for whom a given personality construct is chronically accessible are more likely to remember and describe other 
people in those terms. Individual chronic construct or schema accessibility tends to focus perception and recall. While the construct of behavioral integrity is not a lay construct, there are several lay constructs that approximate it, such as integrity, honesty, consistency, sincerity, or hypocrisy. The following proposition emerges:

PROPOSITION 7. The perceiver's chronic accessibility for lay constructs related to $\mathrm{Bl}$ (e.g., integrity, honesty, consistency, sincerity, or hypocrisy) will enhance the sensitivity of her Bl ascriptions to managers' actual worddeed alignment or misalignment.

\section{An Accelerating Loop at BI Perception: Vigilance and the Priming Effect}

Fiske and Taylor (1991) describe one of the fundamental principles of social cognition in which people tend to look primarily for evidence that supports their preexisting expectations, rather than considering the full array of avail- able information. Schema-congruent information is more readily perceived and recalled. Fiske and Taylor argue that the schemacongruent recall effect is especially pronounced when people are asked to make complex judgments. The assessment of $\mathrm{BI}$ is complex, and so is especially vulnerable to bias by prior expectations or schema congruity. As people come to expect a given level of $\mathrm{BI}$, they filter their perceptions to confirm to their expectations. Thus, perceptions of behavioral integrity are likely to develop a level of "inertia." This inertia might account for Robinson's (1996) finding that employees with a higher initial level of trust were less likely to perceive psychological contract breaches, and may, in the face of strong positive beliefs, give rise to a perceptual threshold effect for word-deed misalignment.

To this perceptual inertia is added an acceleration process: The priming effect (Bruner 1957, Fiske and Taylor 1991) describes how the cognitive accessibility of categories or perceptual dimensions can be stimulated by simple reminders of that category. The priming of a schema increases the likelihood of its subsequent application by the perceiver (Fiske and Taylor 1991). Thus, people who notice a lack of behavioral integrity on the part of another are likely to become increasingly vigilant regarding the construct of $\mathrm{BI}$, and, perhaps, to interpret ambiguous stimuli as further evidence for low Bl.2 Rousseau (1995) describes how employee mistrust of management and a history of troubled relationships can trigger employees to monitor their psychological contracts more closely, and thus to increase the likelihood that they will notice breaches. Morrison and 
Robinson (1997) describe the phenomenon of vigilance as a factor that increases employees' noticing of unmet promises, and they point out that breach influences trust, which in tum influences vigilance. Thus, the perception of word-deed misalignment enhances readiness to perceive future word-deed misalignment. Consideration of this perceptual factor leads to the following proposition:

PROPOSITION 8. A perception of word-deed misalignment at Time 1 will, other things being equal, increase the likelihood of noticing misalignment at Time 2.

\section{Behavioral Antecedents: When Will Managers' Words Actually Diverge From Actions?}

The preceding section considered factors that influence the perception of managers' word-deed alignment given a set of managerial words and deeds. The focus now shifts to a consideration of factors that influence the manager's actual alignment between words and deeds-which presumably serves as the basis for perception. We recognize that such actual alignment is an abstraction that is not measurable, as managers produce many words and many deeds. However, the distinction between the actual word- deed alignment pattern and the perceived pattern is necessary for the differentiation of the various antecedents to BI. With reference to Figure 1, we have completed discussion of Block B and continue to move leftward in the model to Block C.

Several management theorists have considered why managers' espoused practices and values often diverge from those they enact. Most of these arguments may be condensed into three general observations:

(1) Diverse Demands. Managers are frequently charged with the task of satisfying multiple, often contradictory, constituencies, both inside and outside the organization. Relaxed demands for consistency allow them to better accomplish this task (Brunsson 1989, Meyer and Rowan 1977, Pfeffer 1981).

(2) Wishful Thinking. Language often helps shape reality. Thus, managers might espouse their stretch goals and wishful thinking in an effort to elevate themselves and their organizations through processes similar to selffulfilling prophecies and Pygmalion effects (Brunsson 1989, March 1979, Pfeffer 1992). 
(3) Learning by Talking. Managers often figure out what they value from reflecting on their utterances (March 1979, Weick 1995). Constraining managerial talk to issues that are already fully articulated might stifle managerial learning and innovation processes (Brunsson 1989, March 1979, Pfeffer 1992, Weick 1995).

These three processes suggest that inconsistency has potential benefits to organizations and to individual managers. Successful organizations and managers clearly need to manage constituencies, to set goals, and to learn, adapt, and change. Thus, the benefits described above are important to organizational success. The following section will draw on these arguments and others to articulate factors that are likely to cause managers' words and deeds to diverge.

\section{Industrial and Organizational Structure: Need to Satisfy Diverse Stakeholders}

Brunsson (1989) notes that divergence between espoused and enacted values is often a reasonable effort at managing the perceptions of diverse constituencies. Further, Brunsson notes that organizations and industries vary in the extent to which managers must address the perceptions of diverse constituencies to gamer resources and legitimacy. In the government committees Brunsson studied, this need is high. In universities, the need is moderate, while a small manufacturer would face relatively little of this challenge. Publicly traded organizations must manage diverse stakeholders more than privately held firms. The task demands of some managerial jobs, deter- mined in part by industry and organization structure, encourage managers to represent themselves differently to different constituencies. These diverse self-presentations, when noticed by employees, can be expected to affect behavioral integrity. Thus,

PROPOSITION 9. The greater an organization's need to manage the perceptions of diverse stakeholders, the lower the pattern of alignment between managers ' words and deeds, and thus the lower employees' ascriptions of their managers' Bl.

\section{Institutional Forces: Managerial Fads and Fashions}

Managerial fads and fashions (Abrahamson 1991) and the organizational and managerial responses to such fads are another key source of low fit between words and actions. Ghoshal and Bartlett (1996) note that the average company, between 1990 and 1994, had committed 
itself to 11.8 of 25 currently popular management tools and techniques. Abrahamson (1996) notes that fully a third of all U.S. organizations with more than 500 employees reported adopting quality circles between 1980 and 1982 , including $90 \%$ of the Fortune 500 . However, $80 \%$ of the Fortune 500 companies that adopted quality circles in the early 1980s had dropped them by 1987. It is clear that several management practices have waxed and waned in popularity, and that the cycle time of program acceptance and rejection is at times quite rapid. Many companies have taken to embracing and rejecting different managerial approaches in rapid sequence.

Abrahamson (1991) notes that management fashions often serve the function of signaling innovativeness but do little to boost economic profit, and speculates that one explanation would be the notion that managerial technologies are seldom given a chance to work. Abrahamson (1996) points out that constant change in espoused beliefs about management is in part necessitated by the need of managers to appear to be at the forefront of management progress. Managers' individual needs to maintain a competitive edge drive them to use the latest, presumably most advanced, managerial terminologies and techniques, and give them an appetite for ever newer management approaches, with which the competition is hopefully not yet familiar. The 1980s saw an explosion of consultants and management books as companies sought to respond to new competitive threats by adopting new management technologies. Much of the change process, though, focused on superficial trappings (Kouzes and Posner 1993, p. 22). It is a profound irony that management practices adopted to muster institutional credibility (Zucker 1986) have in many cases had precisely the opposite effect in the eyes of employees.

Meyer and Rowan (1977) argue that organizations adopt widely accepted managerial practices to gamer legitimacy and resources and to serve this symbolic function, these practices need not be fully integrated with core production activities; they may be "decoupled" from them. Choi (1995) provides an excellent illustration of this motive and process: He documents that several automotive parts suppliers, to qualify to sell to OEMs, implemented statistical process control (SPC) and other similar programs in a largely superficial manner. While such implementation yielded little if any productivity gains, it was sufficient to secure lucrative contracts.

When organizations experiment with managerial fashions, the firstand sometimes only-element they import is the jargon. Jobs are sometimes retitled, for example, in an effort to manage job prestige and employee 
attitude. Shapiro (1995), however, argues that the use of egalitarian language without concomitant change in underlying dynamics simply obscures the true power structure from less savvy employees and ultimately undermines their effectiveness. While it seems likely that new terminology might influence how organization members function, any lasting impact must be supported by a coordinated change effort (see e.g., Argyris 1970). In the absence of such coordination, or when program support is withdrawn or supplanted by a new management framework, remnants of the old language will often remain within the organization after the underlying values have been forgotten. When the language does not match the reality, behavioral integrity is eroded.

Argyris (1990) notes that espoused and enacted "rulebooks" often diverge as a consequence of companies' dabbling in managerial fads. When the official policies and managerial philosophy statements of a company do not match the way things really get done on a day-to-day basis, smart organizational members learn quickly to discard the official rulebook and play by the true rules of the game. The mismatch between the two "rulebooks" represents grounds for questioning the behavioral integrity of an organization's management, because it is fundamentally an incongruence between the espoused and the enacted. These considerations lead to two further propositions:

PROPOSITION 10. Sequentially supplanted organizational change projects will tend to reduce the actual alignment between managers' words and deeds, and so reduce Bl. This effect might generalize to all failed organizational change efforts.

PROPOSITION 11. The application of managerial technologies absent systematic integration will tend to reduce the actual alignment between managers' words and deeds, and so reduce BJ.

\section{Organizational Processes: Change}

Managers' word-deed misalignments can emerge from partial or sequential abortive change efforts, as detailed above, but may also emerge during the process of sustained change efforts because change can lead to confusion and miscommunication, and different elements of the organization frequently change at different paces. Robinson (1996, p. 574) notes that "constant contract change means increased opportunities for employees and employers to misunderstand the agreement and to perceive a contract breach even when an actual breach did not occur." 
Because the assessment of behavioral integrity is subjective, misunderstandings that emerge from policies and procedures in flux can reduce employees' ascriptions of their managers' behavioral integrity. Further, different elements within the organization's structure are likely to adopt new approaches at different paces. When this occurs, employees will often hear different "messages" from different parts of the organization.

Change can also threaten word-action fit as managers verbally express their hopes for what the organization is to become. When and if these hopes prove infeasible, employees may ascribe the resulting gap between word and deed-or promise and follow-through-to managers' low behavioral integrity. Brunsson (1989) describes managers' talk as an expression of wishful thinking, while production is an expression of what is practical. Brunsson (1993) notes that limits in knowledge, resources, and opportunities for control often constrain the implementation of wishes. These unimplemented decisions, in turn, are often interpreted as hypocrisy (Pfeffer 1992). While this argument sounds disparaging of unrealistic managers, there is certainly value in stretching for the impractical, as the very ideas which best express ideals and aspirations are often difficult to implement (Brunsson 1993). However, the process of managers laying out broad "visions" that are not immediately implemented may be perceived by employees as word-deed misalignment, and thus affect ascriptions of managerial behavioral integrity.

Managerial talk may also diverge from action as a part of learning. March (1979, p. 79) describes divergence between the espoused and the enacted as bad actions with good intentions: "A bad man with good intentions may be a man experimenting with the possibility of becoming good." Thus, much managerial espousal of notions like empowerment may be a function of their personal experimentation. Weick (1995) proposes that managers ' talk is a vital part of their sensemaking process, and that overemphasis on consistency is likely to cause managers to limit their explorations to issues that are already well known-in short, to cease experimentation and learning. Divergence between words and deeds can emerge from managers' self-improvement efforts.

Organizational change processes seem almost inevitably to risk employee perceptions of low $\mathrm{BI}$, because different elements of the organization change at different speeds and are thus temporarily misaligned, and managers speak of hopes and policies as yet unimplemented, and explore, experiment, and experience confusion. These consequences of change warrant consideration when organizations 
contemplate change, and they call for careful management when organizations undertake change.

PROPOSITION 12. Organizational change processes, ceterus paribus, entail a risk of generating real or perceived misalignments between managers' words and deeds, and thus reducing BI. Employee ascriptions of managers' behavioral integrity are likely to be lower during times of organizational transition than during times of stability.

\section{Organizational Processes: Poorly Integrated or Inconsistent Policies}

Policies, procedures, and goals that are mutually incompatible, or ineffective in their stated purposes, can be perceived by employees as word-deed misalignments. Mayer and Davis (1996) found that replacement of a performance appraisal system that was perceived to be invalid with one perceived to be valid increased employee trust in management. Sitkin and Stickel (1996) describe a trust problem that emerged from managerial control systems that were perceived to be incongruent with the performed tasks. 3 It is evident that ineffective policies and procedures can undermine employee trust in management. This undermining might emerge from perceptions of poor behavioral integrity, perceptions of value incongruence, a combination of the two, or questions about managerial competence. The above discussion suggests the following proposition:

PROPOSITION 13. Policies and procedures that do not accomplish their stated intent are often perceived as misalignments between managers' words and deeds, and so are likely to reduce $B$ I.

\section{Individual Processes: Ambivalent Responses to Change}

Word-deed misalignment can also emerge from managers' individual resistance to change efforts. In such cases, the manager will often try to put up an appearance of supporting the change project while actual behavior re- mains unchanged (Schein 1992). Shapiro (1995, p. 91) describes the ambivalent or insecure manager 's response to empowerment programs as "sabotage," and admonishes such managers to refrain from using empowerment jargon because this use will only raise false expectations on the part of employees. When managers find themselves torn between the demands of their superiors and their personal preferences, or between the management practices they believe to be desirable and those with which they feel most comfortable, they are likely to send different messages through their words and their actions. 
PROPOSITION 14. Managers' personal ambivalence about ongoing change efforts often leads to misalignments between words and deeds, and so affects $B I$.

\section{Individual Processes: Self-Knowledge}

Self-knowledge can be expected to affect the actual alignment between managers' words and deeds. A manager can only represent her priorities and preferences accurately if she knows what they truly are. A lack of self- understanding can easily lead to unintended inaccuracies in self-portrayal, and to unanticipated changes and inconsistent behavior. Weick (1995) describes managers as constantly attempting to figure out their personal and professional values from reflecting on their words and actions. Kouzes and Posner (1993, p. 60) describe the vulnerability of this phenomenon:

If leaders are not clear about what they believe in, they are much more likely to change their positions with every fad or opinion poll. Without core beliefs and with only shifting positions, would-be leaders will be judged as inconsistent and will be derided for being "political" in their behavior. The first step on the credibility journey is thus clarification of values.

Management education, then, represents a two-edged sword: To the extent that it promotes efforts to implement the latest management fad, it threatens word-deed alignment and so threatens behavioral integrity. To the extent that it promotes introspection and clarification of the manager's own values, it may enhance behavioral integrity.

PROPOSITION 15. Management development processes that enhance personal value clarification will enhance the alignment between managers' words and deeds, and thus enhance BI.

\section{Individual Processes: Manager Personality Traits}

One can anticipate that personality attributes of individual managers might affect their pattern of actual word-deed alignment, and so affect BI. The personality trait of Self-Monitoring (Snyder 1974), for example, "... presumes consistent patterns of individual differences in the extent to which people regulate their self-presentation by tailoring their actions in accordance with immediate situational cues" (Lennox and Wolfe 1984, p. 1349). People high on the dimension of self-monitoring may be expected to 
display greater cross-situational variability in their conduct and language (Lennox and Wolfe 1984), and this greater variability increases the chance that an observer might notice misalignments and as a result ascribe lower behavioral integrity. While cross-situational behavior variability is in many ways a desirable managerial attribute because it facilitates boundaryspanning performance (Caldwell and O'Reilly 1982), behavioral integrity theory would suggest a potential drawback to this attribute. If, in fact, high self-monitors are described as demonstrating low behavioral integrity, such a case would present an interesting ambivalence regarding the desirability of self- monitoring as a managerial attribute.

The "big five" personality dimension of Conscientiousness (Goldberg 1990) includes such descriptors as consistency, order, self-discipline, and reliability. It seems reasonable to assert that this personality dimension would be associated with high levels of word-action alignment-possibly because managers who are more conscientious will expend greater effort to follow through on expressed commitments.

PROPOSITION 16. Managers' personality traits of self-monitoring and conscientiousness can be expected to affect behavioral consistency, and so to have negative and positive associations, respectively, with Bl.

\section{An Accelerating Loop at the Action Level: Managerial Dissociation}

When a manager's own words and deeds are misaligned with each other for a sustained period of time, mechanisms that resemble internal impression management and the need to appear consistent (Fiske and Taylor 1991) become active to divert managers' attention away from these inconsistencies or potential hypocrisies. Thus, the more a manager's deeds are misaligned with her words, the less aware she becomes of this misalignment- and hence, the more likely she is to enhance and perpetuate it.

Shapiro (1995) describes an array of responses to official slogans and mission statements that are unsupported by actual reward systems in the organization. Some employees will become increasingly frustrated as they attempt to bridge the large gap between the espoused and the actual. Others will become cynical and contemptuous of their leaders. The majority, however, will learn to compartmentalize or dissociate the "speaking" and the "action" parts of their work. It is true that, in many organizations, the manager's path to success seems to lie in verbal endorsements of espoused values, coupled with actual behavior that is in line with more widely accepted implicit norms and standards, and that the 
two elements often do not match. Many managers respond to this kind of environment by accepting it, and by minimizing their awareness and examination of any incongruity between their words and deeds. Argyris (1990, p. 62) notes that managers in an environment where espoused values do not match with actions will talk the espoused while behaviorally following the enacted, and will defensively tend to resist self-examination. Brunsson (1989, p. 227) adds that managers who have low tolerance for hypocrisy, or little "schizophrenic capacity for keeping disparate roles apart" are likely to become depressed in such an environment. In organizations with substantial decoupling between espousal and action, this form of dissociative compartmentalization may be an individually adaptive response.

Social cognition research offers a few models to explain this pattern of behavior. Swann and Read (1981) note that people have preferential recall for behaviors that are consistent with their self-image. To the extent that few people like to think of themselves as speaking one way and acting another, they are unlikely to retrieve evidence that this is the case. Carver's (1979) cybernetic theory of self-regulation notes that self-awareness of behavior that does not match one's own standards, when changing the behavior might entail negative consequences such as un- employment, can lead a person to "disengage mentally," and hence, to stop paying attention to the discrepancy or misalignment. If one knows one is behaving badly, but believes that the wrongdoing is necessary, one tends to tune out awareness of the whole mess. Self-awareness theory (Carver and Scheier 1981) posits that this disengagement results from aversion to the awareness of one' s inadequacy. Fiske and Taylor (1991) summarize extensive research that supports this model of attentional processes in response to evidence of less-than-ideal behavior. This consideration leads to the following propositions:

PROPOSITION 17. Managers will often be unaware of misalignments between their own words and deeds.

PROPOSITION 17A. Misalignments between a man- ager's words and deeds regarding a given issue will, over time, desensitize the manager to further misalignments regarding that issue.

\section{Discussion and Summary}

This paper proposes that behavioral integrity is a construct that warrants further study. $\mathrm{Bl}$ is a key antecedent to trust that describes responses to a wider range of organizational experiences than the 
psychological contract, but is both conceptually and practically simpler than trust. We assert that $\mathrm{BI}$ is highly problematic in today's managerial environment of rapid competitive, technological, and organizational change, that it has profound consequences for employee retention and performance, and that it has been the subject of little direct empirical research. As organizations increasingly address diverse constituencies, as they adapt to increasingly turbulent business environments, and as management fads appear and disappear at ever-increasing speeds, the issue of $\mathrm{Bl}$ is likely to increase in practical importance.

Behavioral integrity is a fundamentally subjective construct that entails internal attributions for managers' pat- terns of word-deed alignment and misalignment. It can be applied to referents at various levels of abstraction, from individual managers, to a generalized notion of the management of a given organization, and perhaps even authority figures in general. The ascription of $\mathrm{BI}$ entails a relatively complex perception and interpretation process that is based on an objective reality, but can be biased by a number of factors. Managers' actual word-deed alignment, which serves as a basis for employees' BI ascriptions, appears to be challenged by managerial fashions and organizational change efforts, individually and in series. These last factors appear to have stimulated the emergence of behavioral integrity as a widespread problem. It should be noted that the sequential model proposed in this paper contains two accelerating loops-one at the stage of actual word-deed alignment, and one at the stage of perception. The presence of these two accelerating loops makes it likely that small word-deed misalignments can have substantial consequences.

The proposal of behavioral integrity as an important construct for empirical research and prescription gives rise to several questions for further exploration. If behavioral integrity ascriptions emerge from assessments of alignment between words and deeds, what happens to assessments of the alignment among different actions? Be- cause managerial actions are often accorded symbolic weight, those assessments might or might not be similar to Bl. A second question regards the possible multi- dimensionality of $\mathrm{BI}$ : Do employees form a unitary judgment of a manager's $\mathrm{BI}$, or can a manager be seen as having high $\mathrm{BI}$ with regard to some values, but not with regard to others? Perhaps this dimensionality varies with the observer's cognitive complexity or engagement. A third question involves the direction of misalignment: If most word-deed misalignment tends to occur in the direction of overpromising and claiming socially desirable managerial values, what of 
the converse situation? In efforts to manage employee perceptions of managers' word-deed alignment, it is critical to know what, if any, is the cost of underpromising. Fourth, there remains a question of whether behavioral integrity assessments shift gradually, or, as Robinson's (1996) work suggests, show a threshold effect. Finally, ethnic culture very likely influences the perception of and response to managers' word-deed misalignment. This influence warrants exploration and articulation.

The Bl framework must not be interpreted to mean that organizations should not experiment with change efforts, that new developments in management science should not receive attention, or that diverse stakeholder desires should be ignored. Rather, it points to trade-offs that must be made intelligently for organizational success, and to a need for techniques that attenuate the costs of the above practices. Practitioners have, since the early days of organizational development writing, stressed the importance of executives' "walking their talk" (McGregor 1967). The behavioral integrity perspective adds to this imperative a reminder of the importance of accurate self- representation. To import a phrase from Weick (1995), managers should consider the virtues of "talking their walk." 


\section{References}

Abrahamson, E. 1991. Managerial fads and fashions: The diffusion and rejection of innovations. Acad. Management Rev. 16(3) 586-612. 1996. Management fashion. Acad. Management Rev. 21(1) 254- 285. Argyris, C. 1970. Intervention Theory and Method: A Behavioral Science

View. Addison-Wesley Publishing, Reading, MA.

------ 1990. Overcoming Organizational Defenses: Facilitating Organizational Learning. Allyn and Bacon, Boston.

Bargh, J. A., F. Pratto. 1986. Individual construct accessibility and perceptual selection. J. Experiment. Soc. Psych. 22 293-31 1. Berscheid, E., W. Graziano, T. Monson, M. Dermer. 1976. Outcome dependency: Attention, attribution, and attraction. J. Personality and Soc. Psych. 34 978-989.

Bies, R. J. 1987. The predicament of injustice: The management of moral outrage. L. L. Cummings, B. M. Staw, eds. Research in Organizational Behavior, vol. 9. JAI Press, Greenwich, CT 289- 319. Bigley, G. A., J. L. Pearce. 1998. Straining for shared meaning in organization science: Problems of trust and distrust. Acad. Management Rev. 23(3) 405-421.

Blancero, D., S. A. Johnson. 1997. Customer service employees and discretionary service behavior: A psychological contract model. Paper presented at Academy of Management National Conference, Boston, MA.

Bruner, J. S. 1957. On perceptual readiness. Psych. Rev. 64 123-152. Brunsson, N. 1989. The Organization of Hypocrisy: Talk, Decisions and Actions in Organizations. John Wiley \& Sons, New York.

------. 1993. Ideas and actions: Justification and hypocrisy as alternatives to control. Accounting, Organ. and Soc. 18(6) 489-506 .

Burt, R. S., M. Knez. 1996. Trust and third-party gossip. R. M. Kramer, T. R. Tyler, Eds. Trust In Organizations: Frontiers of Theory and Research Sage Publications, Inc., Thousand Oaks, CA 68-89.

Butler, J. K., Jr. 1995. Behaviors, trust, and goal achievement in a win-win negotiating role play. Group \& Organ. Management 20(4) 486-501.

Cacioppo, J. T., R. E. Petty. 1989. The elaboration likelihood model: The role of affect and affect-laden information processing on persuasion. P. Cafferata, A. Tybout, Eds. Cognitive and Affective Responses to Advertising. Lexington Books, Lexington, MA. 
Caldwell, D. H., C. A. O'Reilly. III. 1982. Boundary spanning and individual performance: The impact of self-monitoring. J. Applied Psych. 67(1) 124-128.

Carver, C. S. 1979. A cybernetic model of self-attention processes. J. Personality and Soc. Psych. 37 1251-1281.

------, M. F. Scheier. 1981. The self-attention induced feedback loop and social facilitation. J. Experiment. Soc. Psych. 17 545-568.

Choi, T. Y., S. N. Wasti. 1995. Institutional pressures and organizational learning: The case of American-owned automotive-parts suppliers and Japanese shop-floor production methods. J. Liker, J. Ettlie, J. Campbell, Eds. Engineered in Japan: Japanese Technology Management Practices. Oxford University Press, New York.

Creed, W. E. D., R. E. Miles. 1996. Trust in organizations: A conceptual framework linking organizational forms, managerial philosophies, and the opportunity costs of controls. R. M. Kramer, T. R. Tyler, eds. Trust in Organizations: Frontiers of Theory and Re- search Sage Publications Inc., Thousand Oaks, CA. 16-39.

Cummings, L. L., P. Bromiley. 1996. The organizational trust inventory (OTI): Development and validation. R. M. Kramer, T. R. Tyler, eds. Trust In Organizations: Frontiers of Theory and Research Sage Publications, Inc., Thousand Oaks, CA. 302-330.

Eagly, A. H., S. Chaiken. 1993. The Psychology of Attitudes. Harcourt Brace Jovanovich, Orlando, FL.

Erber, R., S. T. Fiske. 1984. Outcome dependency and attention to inconsistent information. J. Personality and Soc. Psych. 47 709-726.

Fiske, S. T., S. E. Taylor. 1991. Social Cognition, 2nd ed. McGraw Hill, New York.

Fox, A. 1974.Beyond Contract: Work, Power, and Trust Relationships. Faber Ltd., London, UK.

Ghoshal, S., C. A. Bartlett. 1996. Rebuilding behavioral context: A blueprint for corporate renewal. Sloan Management Rev. (Winter) 23-36.

Goldberg, L. R. (1990). An alternative "description of personality": The big five factor structure. J. Personality and Soc. Psych. 59(6) 1216--1229.

Greenberg, J. 1990. Looking fair vs. being fair: Managing impressions of organizational justice. L. L. Cummings, B. Staw eds. Research in Organizational Behavior, vol. 12. JAi Press, Greenwich, CT 111-157. Heider, F. 1958. The Psychology of Interpersonal Relations. Wiley, New York.

Higgins, E. T., G. A. King. 1981. Accessibility of social constructs: Information-processing consequences of individual and contextual 
variability. N. Cantor, J. F. Kihlstrom, Eds. Personality. Cognition and Social Interaction. Ehrlbaum, Hillsdale, NJ 69-122.

Hosmer, L. T. 1995. Trust: The connecting link between organizational theory and philosophic ethics. Acad. Management Rev. 20(2) 379403.

Kanter, D. L., P. H. Mirvis. 1989. The Cynical Americans: Living and Working in an Age of Discontent. Jossey-Bass, San Francisco, CA. Kelley, H. H. 1967. Attribution theory in social psychology. D. Levine, ed. Nebraska Symposium on Motivation, vol. 15. University of Nebraska Press, Lincoln, NE.

Kouzes, J. M., B. Z. Posner. 1993. Credibility: How Leaders Gain and Lose It, Why People Demand It. Jossey-Bass, San Francisco, CA.

Kramer, R. M. 1996. Divergent realities and convergent disappointments in the hierarchic relation: Trust and the intuitive auditor at work. R. Kramer and T. Tyler, eds. Trust in Organizations: Frontiers of Theory and Research. Sage Publications, Inc., Thousand Oaks, CA 216-245.

------. 1999. Trust and distrust in organizations: Emerging perspectives, enduring questions. Ann. Rev. Psych. 50 569-598.

Lennox, R. D., R. N. Wolfe. 1984. Revision of the self-monitoring scale. J. Personality and Soc. Psych. 46(6), 1349-1364.

Lewicki, R. J., B. B. Bunker. 1996. Developing and maintaining trust in work relationships. R. Kramer, T. Tyler, eds. Trust In Organizations: Frontiers of Theory and Research. Sage Publication s, Inc., Thousand Oaks, CA. 114-139.

-------, D. J., McAllister, R. J. Bies. 1998. Trust and distrust: New relationships and realities. Acad. Management Rev. 23(3) 438-458.

March, J. G., J. Polsen, eds. 1979. The technology of foolishness. J. M. a. J. Olson, Ed. Ambiguity and Choice in Organizations, 2nd ed. Universitetsforlaget, Oslo, Norway. 69-81.

------, H. A. Simon. 1958. Organizations. John Wiley \& Sons, New York.

Mayer, R. C., J. H. Davis. 1996. Opening the black box of trust for management: Can trust levels be managed? Paper presented at Academy of Management Annual Conference, Cincinnati, $\mathrm{OH}$.

------, ------, F. D. Schoorman. 1995. An integrative model of organizational trust. Acad. Management Rev. 20(3) 709-734.

McAllister, D. J. 1995. Affect- and cognition-based trust as foundations for interpersonal cooperation in organizations. Acad. Management J. 38 24-59. 
Mccroskey, J. C., T. J. Young. 1981. Ethos and credibility: The construct and its measurement after three decades. Central States Speech J 32, 24-34.

McGregor, D. (1967). The professional manager. McGraw-Hill, New York. McLean Parks, J. 1997. The fourth arm of justice: The art and science of revenge. R. Lewicki, B. Sheppard, R. Bies, eds. Research on Negotiation in Organizations. JAi Press, Greenwich, CT 113- 144. Meyer, J. W., B. Rowan. 1977. Institutionalized organizations: Formal structure as myth and ceremony. Amer. J. Soc. 83 340-363.

Mishra, A. K. 1996. Organizational responses to crisis: The centrality of trust. R. Kramer, T. Tyler, eds. Trust in Organizations; Frontiers of Theory and Research. Sage Publication s, Inc., Thousand Oaks, CA 261-287.

Morrison, E. W., S. L. Robinson. 1997. When employees feel betrayed: How psychological contract violation develops. Acad. Management Rev. 22(1) 226-256.

O'Keefe, D. J. 1990. Persuasion Theory and Research. Sage, Newbury Park, CA.

Pfeffer, J. 1981. Management as symbolic action: The creation and maintenance of organizational paradigms. L. Cummings, B. Staw, eds. Research in Organizational Behavior, vol. 3. JAi Press, Greenwich, CT 1-52.

------. 1992. Managing with Power: Politics and Influence in Organizations. Harvard Business School Press, Boston, MA.

Random House College Dictionary, rev. ed. 1975. Random House, New York.

Reeder, G. A., M. B. Brewer. 1979. A schematic model of dispositional attribution in interpersonal perception. Psych. Rev. 86 61-79.

Robinson, S. L. 1996. Trust and breach of the psychological contract. Admin. Sci. Quart 41 574-599.

Rousseau, D. 1995. Psychological Contracts in Organizations: Understanding Written and Unwritten Agreements. Sage Publications, Thousand Oaks, CA.

-------, J. McLean Parks. 1993. The contracts of individuals and organizations. L. Cummings, B. Staw, eds. Research in Organizational Behavior, vol. 15. JAi Press, Greenwich, CT 1-43.

-----, S. B. Sitkin, R. S. Burt, C. Camerer. 1998. Not so different after all: A cross-discipline view of trust. Acad. Management Rev. 23(3) 393-404.

Schein, E. 1992. Organizational Culture and Leadership, 2nd ed. Jossey-Bass, San Francisco, CA. 
Shapiro, E. 1995. Fad Surfing in the Boardroom: Reclaiming the Courage to Manage in the Age of Instant Answers. Addison-Wesley Publishing Co., New York.

Sitkin, S. B., R. J. Bies. 1993. Social accounts in conflict situations: Using explanations to manage conflict. Human Relations 46(3) 349-370.

------, N. L. Roth. 1993. Explaining the limited effectiveness of legalistic "remedies" for trust/distrust. Org. Sci. 4(3) 367-392.

------, D. Stickel. 1996. The road to hell: The dynamics of distrust in an era of quality. R. M. Kramer, T. R. Tyler, eds. Trust in Organizations: Frontiers of Theory and Research Sage Publications, Inc., Thousand Oaks, CA 196-2 15.

Snyder, M. 1974. The self-monitoring of expressive behavior. J. Personality and Soc. Psych. 30 526-537.

Strong, J. W. 1999. McCormick on Evidence, vol. 1. West Group, St. Paul, Minn.

Swann, W. B., S. J. Read, 1981. Acquiring self-knowledge: The search for feedback that fits. J. Personality and Social Psych. 41 1119- 1128.

Tyler, T. R., R. M. Kramer. 1996. Whither trust? R. M. Kramer, T. R. Tyler, eds. Trust in Organizations: Frontiers of Theory and Research Sage Publications, Thousand Oaks, CA 1-15.

Weick, K. E. 1995. Sensemaking in Organizations. Sage Publications, Thousand Oaks, CA.

Williamson, 0. 1993. Calculativeness, trust and economic organization. J. Law and Economics 34 453-502.

Zand, D. E. 1972. Trust and managerial problem solving. Admin. Sci. Quart. 17 229-239.

Zucker, L. G. 1986. Production of trust: Institutional sources of economic structure, 1840-1920. L. L. Cummings, B. Staw, eds. Research in Organizational Behavior, vol. 8. JAi Press, Greenwich, CT. 53-111. 